\title{
Theoretical Studies of IR and NMR Spectral Changes Induced by Sigma-Hole Hydrogen, Halogen, Chalcogen, Pnicogen, and Tetrel Bonds in a Model Protein Environment
}

\author{
Mariusz Michalczyk $^{1}$ D, Wiktor Zierkiewicz ${ }^{1, *(\mathbb{D})}$, Rafał Wysokiński ${ }^{1}$ and Steve Scheiner ${ }^{2, *(\mathbb{D})}$ \\ 1 Faculty of Chemistry, Wrocław University of Science and Technology, Wybrzeże Wyspiańskiego 27, \\ 50-370 Wrocław, Poland; mariusz.michalczyk@pwr.edu.pl (M.M.); rafal.wysokinski@pwr.edu.pl (R.W.) \\ 2 Department of Chemistry and Biochemistry, Utah State University, Logan, UT 84322-0300, USA \\ * Correspondence: wiktor.zierkiewicz@pwr.edu.pl (W.Z.); steve.scheiner@usu.edu (S.S.)
}

Academic Editor: Jan M.L. (Gershom) Martin

Received: 13 August 2019; Accepted: 10 September 2019; Published: 12 September 2019

\begin{abstract}
Various types of $\sigma$-hole bond complexes were formed with FX, HFY, $\mathrm{H}_{2} \mathrm{FZ}$, and $\mathrm{H}_{3} \mathrm{FT}$ $(\mathrm{X}=\mathrm{Cl}, \mathrm{Br}, \mathrm{I} ; \mathrm{Y}=\mathrm{S}, \mathrm{Se}, \mathrm{Te} ; \mathrm{Z}=\mathrm{P}, \mathrm{As}, \mathrm{Sb} ; \mathrm{T}=\mathrm{Si}, \mathrm{Ge}, \mathrm{Sn})$ as Lewis acid. In order to examine their interactions with a protein, N-methylacetamide (NMA), a model of the peptide linkage was used as the base. These noncovalent bonds were compared by computational means with $\mathrm{H}$-bonds formed by NMA with $\mathrm{XH}$ molecules $(\mathrm{X}=\mathrm{F}, \mathrm{Cl}, \mathrm{Br}$, I). In all cases, the A-F bond, which lies opposite the base and is responsible for the $\sigma$-hole on the A atom (A refers to the bridging atom), elongates and its stretching frequency undergoes a shift to the red with a band intensification, much as what occurs for the $\mathrm{X}-\mathrm{H}$ bond in a $\mathrm{H}$-bond (HB). Unlike the NMR shielding decrease seen in the bridging proton of a $\mathrm{H}$-bond, the shielding of the bridging A atom is increased. The spectroscopic changes within NMA are similar for $\mathrm{H}$-bonds and the other noncovalent bonds. The $\mathrm{C}=\mathrm{O}$ bond of the amide is lengthened and its stretching frequency red-shifted and intensified. The amide II band shifts to higher frequency and undergoes a small band weakening. The NMR shielding of the $\mathrm{O}$ atom directly involved in the bond rises, whereas the $\mathrm{C}$ and $\mathrm{N}$ atoms both undergo a shielding decrease. The frequency shifts of the amide I and II bands of the base as well as the shielding changes of the three pertinent NMA atoms correlate well with the strength of the noncovalent bond.
\end{abstract}

Keywords: stretching frequency; NMR shielding; atomic charge; NBO; energy decomposition

\section{Introduction}

Our understanding of the H-bond (HB) represents a cornerstone of what has been learned over the years about solvation phenomena and the structure and function of biological systems [1-4]. The energetic and geometric aspects of the HB have raised our recognition of the requirements of a stable protein and the mechanism of countless enzymes. As part of the analysis of such systems, spectroscopic methods are commonly deployed to identify the presence of HBs, and to provide assessments of their strength. In particular, the shifts in certain IR bands or NMR peaks are frequently interpreted as a quantitative measure of the strength of each such bond [5-7]. As examples [3,8,9], the red shift of the A-H stretching frequency is thought to correlate with the strength of the $\mathrm{AH} \cdots \mathrm{B} \mathrm{HB}$, and there is a similar type of relationship for the downfield shift of the NMR peak of the bridging proton.

Recent years have witnessed a growing recognition of a set of newly rediscovered noncovalent bonds. Rather than utilizing a proton as a bridge between a pair of molecules, these related interactions incorporate a more electronegative atom from the right side of the periodic table. Although this bridging atom may have an overall partial negative charge, a detailed examination of its surrounding 
electrostatic potential reveals the existence of what has come to be called a $\sigma$-hole, a small region of positive potential lying directly along the extension of the covalent bond connecting it to the rest of the molecule. Depending upon the column of the periodic table from which this bridging atom is drawn, the resulting noncovalent bond with a nucleophile is designated as a halogen (XB), chalcogen (YB), pnicogen (ZB), or tetrel (TB) bond. Like the HB, this class of bonds [10-36] are similarly derived from a primary electrostatic attraction, supplemented by substantial amounts of charge transfer, polarization, and dispersion components.

These noncovalent bonds have a number of features in common. They are of a strength comparable to or even greater than a HB. Each such bond is strengthened by electron-withdrawing substituents which intensify the $\sigma$-hole. These bonds are usually strengthened as one moves down each column of the periodic table, for example, $\mathrm{Cl}<\mathrm{Br}<\mathrm{I}$. First-row atoms (i.e., $\mathrm{F}, \mathrm{O}, \mathrm{N}$, and $\mathrm{C}$ ) engage in only weak bonds of this type if at all, but can be coaxed into measurable interactions by appropriate substituents or by adding a charge [37-43].

Despite the recent amassing of fundamental information about these noncovalent bonds, their effects upon the IR and NMR spectra have attracted far less attention. The data that have appeared [37,44-54] are informative to be sure, but they do not consider these systems in a systematic manner. As such, a thorough understanding is not available of the manner in which each type of interaction modulates the spectra, or of the processes by which they might do so. Such information would be essential in detecting their presence in a given chemical or biological system. It would also be especially useful if correlations could be established, between certain spectroscopic parameters and the strength or geometry of a given bond, as has proven so very useful for HBs over the years.

The present work represents an attempt to remedy this lack of information. The focus is placed here on proteins where such noncovalent bonds may be an important component in their structure and function. Indeed, sparked by very recent recognition of the importance of such interactions, researchers have begun to search for their presence in previously solved structures and have successfully identified them in a growing number of cases [18,55-62]. That work would be greatly facilitated if one knew the trademark spectroscopic fingerprint with which to search for such bonds.

A number of model systems were generated in which a halogen, chalcogen, pnicogen, or tetrel bond was present. Their interactions with a protein were simulated by using a model of the peptide group as electron donor, in much the same way that the peptide $\mathrm{O}$ atom acts as proton acceptor in so many protein HBs. Quantum calculations evaluated the strength of each interaction, as well as its geometric properties. The effects of each bond upon the IR and NMR spectra of the system were determined and compared with the binding strength, identity of the bond, and nature of the specific bridging atom. In this way, a systematic set of rules was generated that may hopefully assist in identifying these types of bonds in a complicated system, and providing some measure of their strength.

As the goal of this work was to determine how the spectroscopic features of H-bonded systems compared with the same aspects of related noncovalent bonds, a variety of different Lewis acids (i.e., $\sigma$-hole donors) were chosen to cover a broad range in each category. The full range of hydrogen halides, namely, $\mathrm{FH}, \mathrm{ClH}, \mathrm{BrH}$, and $\mathrm{IH}$, represent molecules of varying acidity that donate a proton in a $\mathrm{HB}$. Within the set of halogen-bonding molecules, FCl, FBr, and FI all place an electron-withdrawing $\mathrm{F}$ substituent on the halogen atom so as to create a $\sigma$-hole which can engage with a nucleophile. A similar philosophy was adopted for the other types of Lewis acids. HFS, HFSe, and HFTe cover a range of chalcogen-bonding molecules. Pnicogen-bonding was invoked via $\mathrm{H}_{2} \mathrm{FP}, \mathrm{H}_{2} \mathrm{FAs}$, and $\mathrm{H}_{2} \mathrm{FSb}$, whereas $\mathrm{H}_{3} \mathrm{FSi}, \mathrm{H}_{3} \mathrm{FGe}$, and $\mathrm{H}_{3} \mathrm{FSn}$ represent the set of tetrel-bonding molecules. Of course, one would not expect these molecules themselves to typically be present within a protein environment, as they serve merely as models of larger molecules. With respect to nucleophile, the N-methylacetamide (NMA) unit serves as a commonly invoked model of the protein peptide group. Its $\mathrm{O}$ atom is expected to form not only HBs with proton donors, but also the other types of noncovalent bonds with the various Lewis acids. It was hoped that this choice of base would enable parallels to be drawn to the spectroscopic aspects of these interactions within the confines of a protein. 


\section{Results}

The optimized geometries of some of the sample systems are displayed in Figure 1; others are quite similar. Coordinates of all optimized complexes are available in the Supplementary Materials section. It may be noted that the relative orientations are as would be expected for each of the types of bonds under consideration here, commensurate with the positions of the $\sigma$-holes on each type of Lewis acid, and with the $\mathrm{O}$ atom of NMA serving as the electron donor atom.

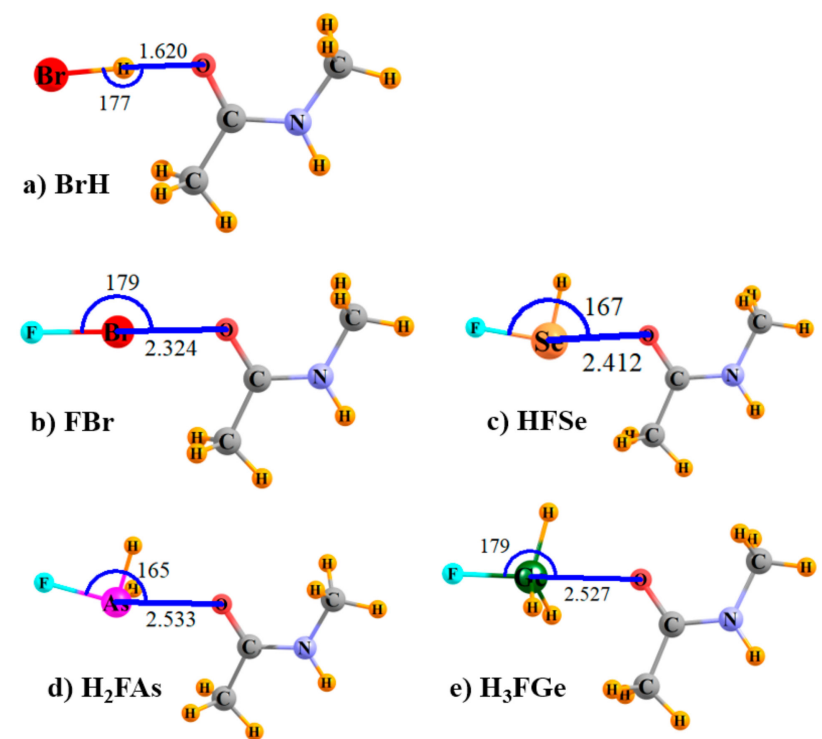

Figure 1. Optimized geometries of indicated Lewis acids with N-methylacetamide (NMA). Distances in $\AA$, angles in degrees.

\subsection{IR Spectra}

The first four rows of Table 1 reiterate the types of changes in the monomers that are well known for HBs. The X-H bond of the proton donor is elongated and its stretching band is shifted to the red and intensified. In these particular cases, the stretch of the XH bond increases from $0.032 \AA$ for the smallest $\mathrm{X}=\mathrm{F}$ atom up to $0.069 \AA$ for the largest $\mathrm{X}=\mathrm{I}$. The red shift is equal to approximately $600-700 \mathrm{~cm}^{-1}$ for the entire range of $X$ atoms. The intensification of the band is expressed as the ratio of the intensity within the complex to that within the HX monomer. This quantity is 14 for HF and increases up to 147 for $\mathrm{HBr}$, and then makes a large jump to nearly 48,000 for HI. The changes occurring within the proton acceptor NMA molecule are somewhat smaller but still easily detectable. Upon forming a HB with each HX molecule, the $\mathrm{C}=\mathrm{O}$ bond of NMA elongates by $0.01 \AA$. Its stretching frequency, commonly known as the amide I band, shifts to the red by $30-170 \mathrm{~cm}^{-1}$, and becomes more intense by a factor of 1.6-10. In each case, the magnitude rises along with the size of the $\mathrm{X}$ atom, that is, $\mathrm{F}<\mathrm{Cl}<\mathrm{Br}<\mathrm{I}$. The amide II band is a combination of $\mathrm{C}-\mathrm{N}$ stretch and $\mathrm{N}-\mathrm{H}$ bend. This mode shifts to the blue by $25 \mathrm{~cm}^{-1}$, with little sensitivity to the identity of $X$. There is a small diminution of its intensity for the three lighter $X$ atoms, and an intensification for $\mathrm{HI}$.

The lower portions of Table 1 refer to halogen, chalcogen, pnicogen, and tetrel bonding, abbreviated as $\mathrm{XB}, \mathrm{YB}, \mathrm{ZB}$, and $\mathrm{TB}$, respectively. The general patterns for all of these types of noncovalent bonds echo the changes observed for HBs. The bond within the Lewis acid molecule that engages with the partner NMA elongates, and its stretching mode shifts to the red and becomes more intense. Just as in the case of HBs, the $\mathrm{C}=\mathrm{O}$ bond of NMA also becomes longer, shifts to the red, and intensifies. The changes induced in the amide II band are also quite similar to those caused by HB formation, and of comparable magnitude. 
Table 1. Changes in internal bond lengths $(\AA)$, stretching frequencies $\left(\mathrm{cm}^{-1}\right)$, and band intensification resulting ${ }^{\mathrm{a}}$ from complex formation.

\begin{tabular}{|c|c|c|c|c|c|c|c|c|}
\hline- & $\Delta \mathrm{r}(\mathrm{X}-\mathrm{H})$ & $\Delta v(\mathrm{X}-\mathrm{H})$ & $\mathbf{I}_{\text {comp }} / \mathbf{I}_{\text {mon }}$ & $\begin{array}{c}\Delta \mathrm{r} \\
(\mathrm{C}=\mathrm{O})\end{array}$ & $\begin{array}{c}\Delta v \\
(\mathrm{C}=\mathrm{O})^{\mathrm{b}}\end{array}$ & $\mathbf{I}_{\text {comp }} / \mathbf{I}_{\text {mon }}$ & $\begin{array}{c}\Delta v(\text { Amide II } \\
\text { Band) }^{\mathrm{c}}\end{array}$ & $I_{\text {comp }} / I_{\text {mon }}$ \\
\hline FH $\cdots$ NMA & 0.032 & -729 & 14.0 & 0.012 & -30 & 1.6 & +26 & 0.9 \\
\hline $\mathrm{ClH} \cdots \mathrm{NMA}$ & 0.051 & -695 & 48.6 & 0.013 & -50 & 2.8 & +25 & 0.9 \\
\hline $\mathrm{BrH} \cdots \mathrm{NMA}$ & 0.060 & -705 & 146.8 & 0.014 & -75 & 4.8 & +26 & 0.8 \\
\hline $\mathrm{IH} \cdots \mathrm{NMA}$ & 0.069 & -606 & $47,960.0$ & 0.014 & -169 & 10.1 & +25 & 1.8 \\
\hline XB & $\Delta \mathrm{r}(\mathrm{F}-\mathrm{X})$ & $\Delta v(\mathrm{~F}-\mathrm{X})$ & & & & & & \\
\hline FCl $\cdots \mathrm{NMA}$ & 0.042 & -103 & 10.5 & 0.013 & -45 & 2.2 & +22 & 0.9 \\
\hline FBr $\cdots \mathrm{NMA}$ & 0.048 & -80 & 6.8 & 0.017 & -55 & 2.5 & +30 & 0.8 \\
\hline 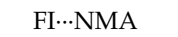 & 0.044 & -58 & 4.4 & 0.019 & -55 & 2.6 & +35 & 0.7 \\
\hline YB & $\Delta \mathrm{r}(\mathrm{F}-\mathrm{Y})$ & $\Delta v(\mathrm{~F}-\mathrm{Y})$ & & & & & & \\
\hline 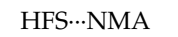 & 0.030 & -71 & 3.7 & 0.009 & -28 & 1.8 & +19 & 1.0 \\
\hline HFSe $\cdots$ NMA & 0.039 & -64 & 3.4 & 0.013 & -36 & 2.1 & +25 & 0.9 \\
\hline HFTe $\cdots$ NMA & 0.041 & -56 & 2.6 & 0.016 & -49 & 2.3 & +30 & 0.8 \\
\hline ZB & $\Delta \mathrm{r}(\mathrm{F}-\mathrm{Z})$ & $\Delta v(\mathrm{~F}-\mathrm{Z})$ & & & & & & \\
\hline $\mathrm{H}_{2} \mathrm{FP} \cdots \mathrm{NMA}$ & 0.024 & -58 & 2.3 & 0.008 & -24 & 1.7 & +15 & 1.0 \\
\hline $\mathrm{H}_{2} \mathrm{FAs} \cdots \mathrm{NMA}$ & 0.032 & -54 & 2.2 & 0.010 & -29 & 1.8 & +20 & 1.0 \\
\hline $\mathrm{H}_{2} \mathrm{FSb} \cdots \mathrm{NMA}$ & 0.036 & -51 & 1.9 & 0.013 & -40 & 1.9 & +25 & 0.9 \\
\hline $\mathrm{TB}$ & $\Delta \mathrm{r}(\mathrm{F}-\mathrm{T})$ & $\Delta v(\mathrm{~F}-\mathrm{T})$ & & & & & & \\
\hline $\mathrm{H}_{3} \mathrm{FSi} \cdots \mathrm{NMA}$ & 0.024 & -57 & 3.2 & 0.008 & -23 & 1.5 & +17 & 1.0 \\
\hline $\mathrm{H}_{3} \mathrm{FGe} \cdots \mathrm{NMA}$ & 0.031 & -57 & 2.0 & 0.009 & -25 & 1.6 & +20 & 1.0 \\
\hline $\mathrm{H}_{3} \mathrm{FSn} \cdots \mathrm{NMA}$ & 0.034 & -50 & 1.7 & 0.013 & -35 & 1.8 & +28 & 0.9 \\
\hline
\end{tabular}

${ }^{\text {a }}$ MP2/aug-cc-pVDZ level; ${ }^{b}$ amide I band, primarily $\mathrm{C}=\mathrm{O}$ stretch; ${ }^{c}$ combination of $\mathrm{C}-\mathrm{N}$ stretch and $\mathrm{N}-\mathrm{H}$ bend.

Systematic patterns also occur in the data. The magnitudes of the changes within the $\sigma$-hole donor follow the general decreasing order of $\mathrm{XB}>\mathrm{YB}>\mathrm{ZB} \sim \mathrm{TB}$. The bond elongations generally increase along with a larger atom (e.g., $\mathrm{P}<\mathrm{As}<\mathrm{Sb}$ ), whereas the spectroscopic changes follow an opposite pattern, diminishing with a larger atom. While the bond stretches are roughly of the same magnitude as observed in the HBs, the spectroscopic data are much smaller. For example, the formation of a HB by $\mathrm{ClH}$ shifts its stretching frequency by $700 \mathrm{~cm}^{-1}$, and intensifies the band by a factor of 50 , whereas the $\mathrm{FCl}$ bond is red-shifted by only $100 \mathrm{~cm}^{-1}$, and intensifies by 10 -fold.

With regard to the NMA electron donor, the perturbations also follow the $\mathrm{XB}>\mathrm{YB}>\mathrm{ZB} \sim \mathrm{TB}$ order. Within any given class of bond (e.g., chalcogen), all parameters, such as bond stretch, red shift, and intensification, grow in magnitude as the atom in question becomes larger (e.g., $\mathrm{S}<\mathrm{Se}<$ $\mathrm{Te})$. These perturbations are comparable to those noted as a result of HB formation. In summary, the IR perturbations to the spectra of both electron acceptor and donor molecules within any of these noncovalent bonds are quite similar to those expected for HBs, notwithstanding the larger changes in the HB proton donor's stretching frequency, which are due in part to the much lighter mass of the bridging proton.

\subsection{NMR Spectra and Atomic Charges}

Tables S1 and S2 (Supplementary Materials) display the NMR isotropic chemical shielding of each of the unperturbed monomers, and the analogous data for the optimized complexes are contained in Table S3 (Supplementary Materials). More importantly, Table 2 lists the changes in the NMR isotropic chemical shielding of the various relevant atoms resulting from the formation of each of the noncovalent bonds. The topmost section of data reflects the deshielding that occurs on the bridging proton as a result of HB formation. This deshielding varies from $7 \mathrm{ppm}$ for $\mathrm{FH}$ up to $11 \mathrm{ppm}$ for $\mathrm{BrH}$ and IH. In contrast, the other bridging atoms, whether $X, Y, Z$, or $T$, all undergo an increase in their shielding. The magnitude of this change is largest for $X$, then decreases in the order of $Y>Z>T$. For each class of bond, the shielding increase rises dramatically along with the size of the atom. For example, the $\mathrm{Cl}, \mathrm{Br}$, and I atoms of the XB complexes increase their shielding by 239, 929, and 2197 ppm, respectively. 
Table 2. Changes of NMR chemical shielding (ppm) caused by complexation ${ }^{\mathrm{a}}$.

\begin{tabular}{|c|c|c|c|c|c|}
\hline \multicolumn{3}{|c|}{ System } & \multicolumn{3}{|c|}{ Atoms } \\
\hline HB & $\mathrm{H}$ & $X$ & $\mathrm{O}$ & $C^{b}$ & $\mathrm{~N}$ \\
\hline $\mathrm{FH} \cdots \mathrm{NMA}$ & -6.9 & -19.5 & 34.4 & -6.3 & -5.1 \\
\hline $\mathrm{ClH} \cdots \mathrm{NMA}$ & -9.5 & -1.0 & 20.0 & -6.0 & -5.4 \\
\hline $\mathrm{BrH} \cdots \mathrm{NMA}$ & -10.6 & 35.8 & 15.4 & -6.2 & -5.6 \\
\hline IH $\cdots$ NMA & -11.2 & 175.7 & 7.0 & -6.1 & -5.7 \\
\hline XB & $X$ & $\mathrm{~F}$ & & & \\
\hline $\mathrm{FCl} \cdots \mathrm{NMA}$ & 239.3 & -139.2 & 28.4 & -5.4 & -5.4 \\
\hline 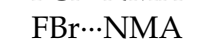 & 929.2 & -208.8 & 46.5 & -7.1 & -7.7 \\
\hline 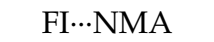 & 2196.7 & -296.2 & 62.6 & -7.8 & -9.9 \\
\hline $\mathrm{YB}$ & $\mathrm{Y}$ & F & & & \\
\hline HFS $\cdots$ NMA & 141.2 & -112.0 & 28.1 & -4.0 & -4.6 \\
\hline HFSe $\cdots$ NMA & 521.2 & -151.9 & 38.8 & -4.9 & -6.5 \\
\hline HFTe $\cdots$ NMA & 1310.8 & -193.1 & 49.4 & -7.6 & -8.4 \\
\hline ZB & Z & F & & & \\
\hline $\mathrm{H}_{2} \mathrm{FP} \cdots \mathrm{NMA}$ & 40.0 & -62.2 & 22.0 & -4.0 & -4.3 \\
\hline $\mathrm{H}_{2} \mathrm{FAs} \cdots \mathrm{NMA}$ & 107.6 & -71.1 & 27.5 & -4.5 & -5.5 \\
\hline $\mathrm{H}_{2} \mathrm{FSb} \cdots \mathrm{NMA}$ & 283.9 & -80.6 & 35.2 & -6.3 & -7.2 \\
\hline TB & $\mathrm{T}$ & F & & & \\
\hline $\mathrm{H}_{3} \mathrm{FSi} \cdots \mathrm{NMA}$ & 17.3 & -42.5 & 17.0 & -4.0 & -4.5 \\
\hline $\mathrm{H}_{3} \mathrm{FGe} \cdots \mathrm{NMA}$ & 42.5 & -47.3 & 19.8 & -4.3 & -5.2 \\
\hline $\mathrm{H}_{3} \mathrm{FSn} \cdots \mathrm{NMA}$ & 127.0 & -53.0 & 29.4 & -5.8 & -7.6 \\
\hline
\end{tabular}

a MP2 level, aug-cc-pVDZ basis for all atoms except 4th row I, Te, Sb, and Sn, which used all-electron Sapporo-DKH3-DZP-2012-diffuse; ${ }^{\mathrm{b}} \mathrm{C}$ atom bonded to O.

The $\mathrm{F}$ atom bound to the bridging atom suffers a loss in shielding, also in the same $\mathrm{X}>\mathrm{Y}>\mathrm{Z}>\mathrm{T}$ order. (The $\mathrm{Br}$ and I atoms of $\mathrm{BrH}$ and $\mathrm{IH}$ increase their shielding upon $\mathrm{HB}$ formation.) The $\mathrm{O}$ atom of the NMA $C=\mathrm{O}$ bond raises its shielding, whereas its $\mathrm{C}$ and $\mathrm{N}$ neighbors suffer a drop. Probably owing to its direct involvement in each noncovalent bond, the $\mathrm{O}$ increases are larger in magnitude than the decreases observed in $\mathrm{C}$ and $\mathrm{N}$. The $\mathrm{O}$ increases generally fall into the familiar $\mathrm{X}>\mathrm{Y}>\mathrm{Z}>\mathrm{T}$ pattern. While the $O$ shielding increase diminishes with larger $X$ atom in the $\mathrm{XH} \cdots$ NMA complexes, its increase rises regularly along with larger bridging atom size in the other noncovalent bonds. In contrast, the $\mathrm{C}$ and $\mathrm{N}$ shielding changes show lesser sensitivity to bond type or to bridging atom size. Importantly, the general patterns on all three NMA atoms for the HBs are repeated for the other noncovalent bonds.

Certain points of consistency between the NMR shielding patterns and the changes in natural atomic charge accompany the formation of each of these interactions, as reported in Table 3. Considering first the NMA electron donor molecule, the $\mathrm{O}$ atom generally acquires additional electron density, which is consonant with its enhanced shielding. The drops in the $\mathrm{C}$ and $\mathrm{N}$ shielding can likewise be connected to the reduced negative charges of these atoms. The bridging atoms of the various Lewis acid molecules acquire a larger negative charge as a result of complexation, which is consistent with their increased shielding. On the other hand, the quantitative relationships are not correlated. For example, while the shielding increase of the bridging atoms rises along with the size of this atom, the increased negative charge varies in the opposite direction, that is, smallest for larger atoms. A perhaps even more fundamental discrepancy occurs for the F atoms. Even though each such atom acquires additional negative charge from the complexation process, its shielding drops by a large amount. 
Table 3. Changes of natural atomic charges (e) caused by complexation ${ }^{\mathrm{a}}$

\begin{tabular}{|c|c|c|c|c|c|}
\hline \multicolumn{3}{|c|}{ Donors } & \multicolumn{3}{|c|}{ Atoms } \\
\hline HB & $\mathrm{H}$ & $x$ & $\mathrm{O}$ & C & $\mathrm{N}$ \\
\hline FH $\cdots$ NMA & -0.003 & -0.064 & -0.035 & 0.020 & 0.025 \\
\hline $\mathrm{ClH} \cdots \mathrm{NMA}$ & 0.038 & -0.123 & -0.013 & 0.019 & 0.025 \\
\hline $\mathrm{BrH} \cdots \mathrm{NMA}$ & 0.050 & -0.155 & -0.005 & 0.020 & 0.029 \\
\hline IH $\cdots$ NMA & 0.052 & -0.168 & 0.006 & 0.020 & 0.031 \\
\hline XB & $X$ & F & & & \\
\hline FCl $\cdots \mathrm{NMA}$ & -0.072 & -0.094 & 0.044 & 0.016 & 0.033 \\
\hline 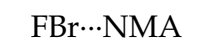 & -0.058 & -0.093 & 0.021 & 0.019 & 0.036 \\
\hline 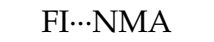 & -0.050 & -0.087 & -0.001 & 0.022 & 0.040 \\
\hline YB & Y & $\mathrm{F}$ & & & \\
\hline HFS $\cdots$ NMA & -0.043 & -0.056 & -0.002 & 0.016 & 0.023 \\
\hline HFSe $\cdots$ NMA & -0.042 & -0.063 & -0.007 & 0.016 & 0.027 \\
\hline HFTe $\cdots$ NMA & -0.013 & -0.063 & -0.023 & 0.022 & 0.035 \\
\hline $\mathrm{ZB}$ & Z & F & & & \\
\hline $\mathrm{H}_{2} \mathrm{FP} \cdots \mathrm{NMA}$ & -0.035 & -0.032 & -0.020 & 0.013 & 0.016 \\
\hline $\mathrm{H}_{2} \mathrm{FAs} \cdots \mathrm{NMA}$ & -0.027 & -0.039 & -0.019 & 0.014 & 0.020 \\
\hline $\mathrm{H}_{2} \mathrm{FSb} \cdots \mathrm{NMA}$ & 0.018 & -0.046 & -0.036 & 0.021 & 0.029 \\
\hline $\mathrm{TB}$ & $\mathrm{T}$ & F & & & \\
\hline $\mathrm{H}_{3} \mathrm{FSi} \cdots \mathrm{NMA}$ & -0.004 & -0.025 & -0.025 & 0.015 & 0.017 \\
\hline $\mathrm{H}_{3} \mathrm{FGe} \cdots \mathrm{NMA}$ & -0.005 & -0.030 & -0.025 & 0.014 & 0.017 \\
\hline $\mathrm{H}_{3} \mathrm{FSn} \cdots \mathrm{NMA}$ & -0.001 & -0.038 & -0.036 & 0.023 & 0.032 \\
\hline
\end{tabular}

a MP2 level, aug-cc-pVDZ basis for all atoms except 4th row I, Te, Sb, and Sn, which used all-electron Sapporo-DKH3-DZP-2012-diffuse.

Of course, the density changes that occur as a result of complexation are more complex than can be fully encapsulated by a simple numerical atomic charge. The actual density shifts are shown as a full three-dimensional map in Figure 2 where increases are shown in purple and losses in green. The systems illustrated in Figure 2 represent the three $\mathrm{ZB}$ systems, but the diagrams for the $\mathrm{XB}, \mathrm{YB}$, and TB bonds are quite similar. (The electron redistribution patterns of all systems are displayed in Figure S1 (Supplementary Materials) at two different contour levels, $\Delta \rho=0.0005$ and 0.0015 au.) It is clear that there are regions of both gain and depletion surrounding each nucleus, and the atomic charge data represent only a broad summation of both effects. For example, while Table 3 indicates an overall increase of electron density on the $\mathrm{F}$ atom, the more detailed examination in Figure 2 shows a region of loss at the F nucleus, with areas of gain along the F-Z axis. Of course, the presence of both gain and loss regions does not imply full cancellation, so the charge changes in Table 3 are not zero. It may be concluded that the depletion close to the nucleus is the major factor responsible for the reduction in the NMR shielding. The $\mathrm{Z}$ atom loses density on the side toward the NMA O atom, but compensates with a gain along the $\mathrm{Z}-\mathrm{F}$ bond. According to Table 3, the green area of loss predominates for $\mathrm{Sb}$, and the opposite occurs for the smaller P and As, which is consistent with the sizes of the lobes in Figure 2, although of course it is difficult to quantify the totals from merely overall lobe size. As for the NMA molecule, all three atoms of interest are centers of both purple and green lobes. However, it is the green depletion lobes which are closest to the $\mathrm{C}$ and $\mathrm{N}$ nuclei which help explain their shielding reduction, whereas the $\mathrm{O}$ nucleus lies within a purple density gain region, larger than the surrounding green area, and so this results in a shielding increase. 


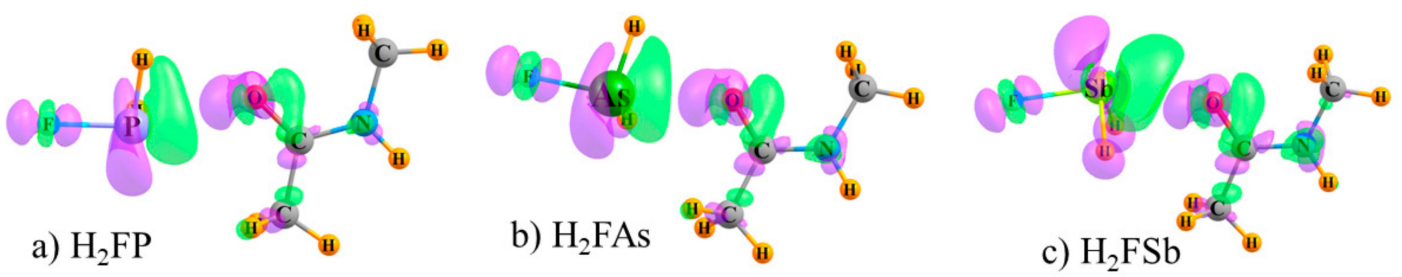

Figure 2. Regions of density gain (purple) and loss (green) in complexes pairing NMA with (a) H2FP, (b) H2FAs, and (c) H2FSb. Contour shown is \pm 0.0015 au.

\subsection{Relation to Binding Energies}

One may expect some correlation between the spectroscopic aspects of these interactions and their energetic strength. The interaction energies of each complex are displayed in Table 4 at three different levels of theory. While the BLYP-D3/Def2TZVPP binding energies (II) are somewhat larger than the two ab initio levels, it is gratifying that the MP2 results in column I are quite similar to the CCSD(T) data in column III, both with the same aug-cc-pVDZ basis set.

Table 4. Interaction energies $\left(\mathrm{E}_{\mathrm{int}}, \mathrm{kcal} \cdot \mathrm{mol}^{-1}\right)$ corrected for basis set superposition error (BSSE) calculated at the MP2/aug-cc-pVDZ (I), BLYP-D3/Def2TZVPP (II), and CCSD(T)/aug-cc-pVDZ (III) levels of theory.

\begin{tabular}{|c|c|c|c|}
\hline System & (I) & (II) & (III) \\
\hline \multicolumn{4}{|l|}{$\mathrm{HB}$} \\
\hline 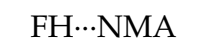 & -12.68 & -14.59 & -12.78 \\
\hline $\mathrm{ClH} \cdots \mathrm{NMA}$ & -10.14 & -11.27 & -9.07 \\
\hline BrH $\cdots$ NMA & -9.22 & -11.37 & -7.80 \\
\hline IH $\cdots$ NMA & -7.23 & -9.24 & -5.38 \\
\hline \multicolumn{4}{|l|}{ XB } \\
\hline FCl $\cdots \mathrm{NMA}$ & -9.69 & -14.88 & -8.49 \\
\hline 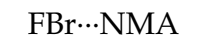 & -13.34 & -16.86 & -11.92 \\
\hline 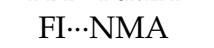 & -15.75 & -17.69 & -14.40 \\
\hline \multicolumn{4}{|l|}{ YB } \\
\hline HFS...NMA & -8.90 & -10.32 & -8.17 \\
\hline HFSe $\cdots$ NMA & -11.18 & -12.37 & -10.21 \\
\hline HFTe $\cdots$ NMA & -13.82 & -13.95 & -12.89 \\
\hline \multicolumn{4}{|l|}{ ZB } \\
\hline $\mathrm{H}_{2} \mathrm{FP} \cdots \mathrm{NMA}$ & -7.40 & -7.21 & -7.00 \\
\hline $\mathrm{H}_{2} \mathrm{FAs} \cdots \mathrm{NMA}$ & -8.65 & -8.53 & -8.13 \\
\hline $\mathrm{H}_{2} \mathrm{FSb} \cdots \mathrm{NMA}$ & -11.40 & -10.63 & -10.93 \\
\hline \multicolumn{4}{|l|}{ TB } \\
\hline $\mathrm{H}_{3} \mathrm{FSi} \cdots \mathrm{NMA}$ & -7.70 & -7.11 & -7.72 \\
\hline $\mathrm{H}_{3} \mathrm{FGe} \cdots \mathrm{NMA}$ & -8.37 & -7.53 & -8.34 \\
\hline $\mathrm{H}_{3} \mathrm{FSn} \cdots \mathrm{NMA}$ & -12.22 & -10.20 & -12.09 \\
\hline
\end{tabular}

As is typically the case in these types of bonds, the interaction grows along with the size of the bridging atom, whether $\mathrm{X}, \mathrm{Y}, \mathrm{Z}$, or $\mathrm{T}$. HB energies are directly related to the acidity of the proton donor and therefore follow the pattern of $\mathrm{HF}>\mathrm{HCl}>\mathrm{HBr}>\mathrm{HI}$. The relationship between the interaction energies and the frequency shifts of the various bands are exhibited in Figure 3. The data presented exclude the HB systems due to their somewhat anomalous behavior with respect to the other noncovalent bonds. For example, $\mathrm{HB}$ energy lessens as the $\mathrm{X}$ atom of $\mathrm{XH}$ grows larger, whereas $\mathrm{XB}$ behaves in the opposite fashion. The green data points refer to the $\Delta v$ band shifts of the $\mathrm{F}-\mathrm{A}$ bond of the Lewis acid (A refers to any of the bridging atoms). There is much scatter and one can conclude that only a poor correlation occurs. Indeed, the correlation coefficient between this frequency shift and the interaction energy is only 0.04 . The two points that are furthest from any linear correlation with the largest red shift correspond to the $\mathrm{FCl}$ and $\mathrm{FBr}$ halogen bonds. However, even if these two outliers are 
removed, the correlation remains poor, with a correlation coefficient of 0.10 . The shifts of the NMA bands are another story, as they are nearly linear functions of the energetics. The red line in Figure 3 relates to the amide I band, whose correlation coefficient with $\mathrm{E}_{\text {int }}$ is 0.90 . Even better is the blue line representing the amide II band with a correlation coefficient of 0.99 . It thus appears that the frequency shifts occurring within the electron donor molecule serve as an excellent indicator of the bond strength in these systems.

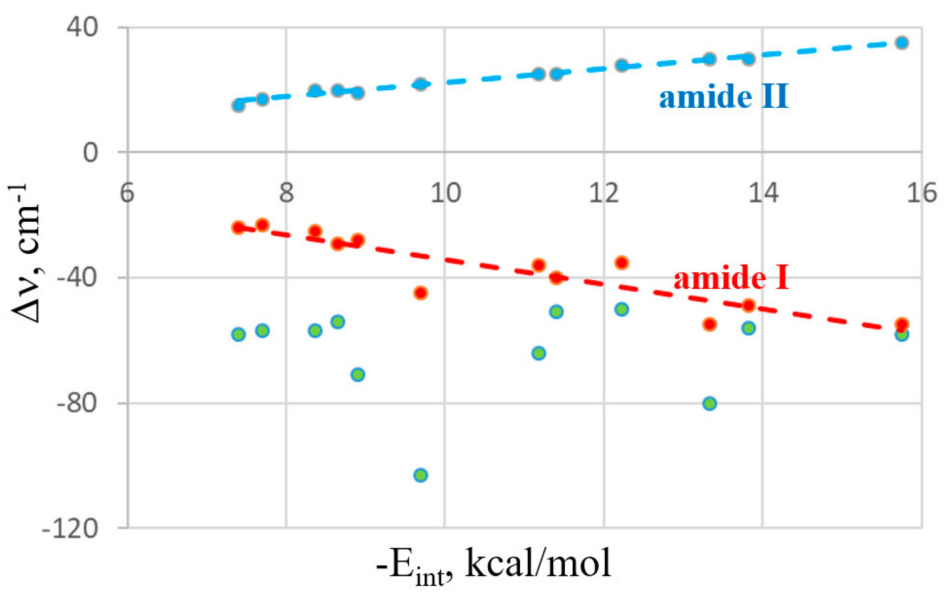

Figure 3. Relationship between MP2/aug-cc-pVDZ interaction energy and changes in frequencies of F-X stretch (green points), amide I (red), and amide II (blue). Broken lines indicate linear fits.

There is also a certain correspondence between the energetics and NMR data. Figure 4 shows a nearly linear relationship with the changes in the NMR chemical shifts of the $\mathrm{O}, \mathrm{C}$, and $\mathrm{N}$ atoms of the NMA electron donor molecule. The correlation coefficients are $0.94,0.95$, and 0.98 , respectively. Again, adding the HB systems to these data sets deteriorates the correlations, dropping them down below 0.90 . The shifts of the bridging $X$ atom do not correlate well at all, as is evident from the large fluctuations in the first column of Table 2. Thus, along with the IR shifts occurring within the electron acceptor, the NMR chemical shifts can also act as a valuable indicator of bond strength.

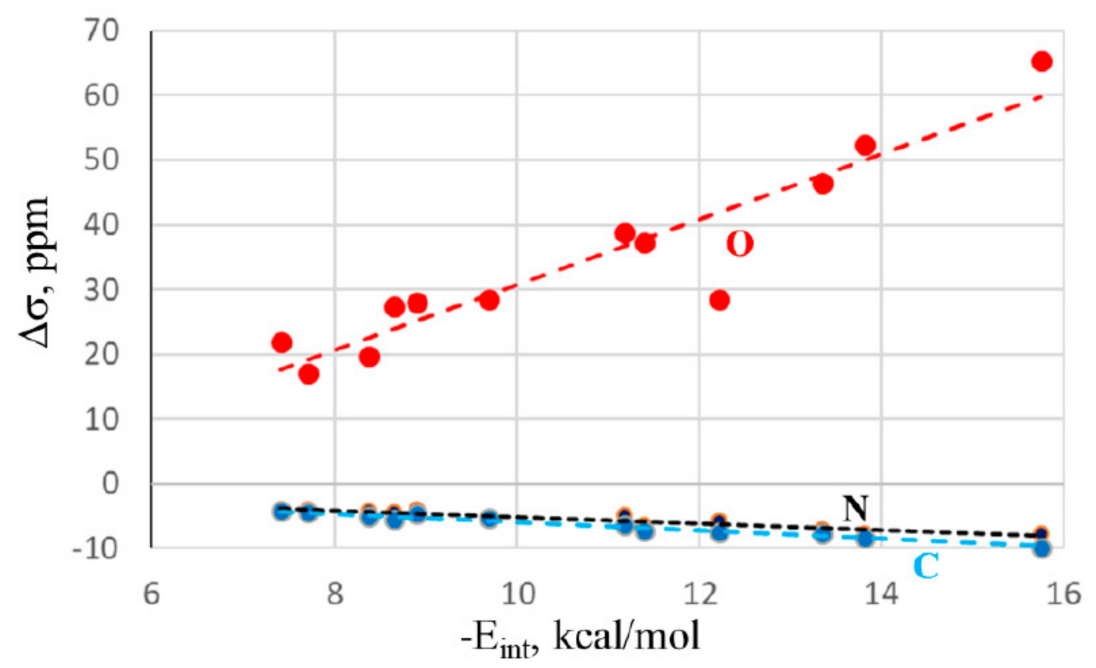

Figure 4. Relationship between MP2/aug-cc-pVDZ interaction energy and changes in NMR shielding of indicated atoms of NMA. Broken lines indicate linear fits.

\subsection{Contributions to Binding Energies}

It is well known that electrostatic attraction in noncovalent bonds such as these is supplemented by orbital interactions and dispersion energy. A decomposition of the total interaction energies into 
its constituent parts was carried out and the results are reported in Table 5. There are similarities between all of these bonds first in that electrostatics account for at least half of the total interaction. This percentage contribution rises with the size of the bridging atom, with the exception of HBs where the opposite trend is noted. Orbital interactions, which include internal polarization and charge transfer, make up a bit less, approximately in the range of $31-47 \%$, and their percentage contribution tends to diminish with larger bridging atoms. Dispersion plays a lesser role, contributing $10 \%$ or less. It is interesting that the dispersion's percentage contribution follows the approximate pattern of $\mathrm{XB}<$ $\mathrm{YB}<\mathrm{ZB} \sim \mathrm{TB}$.

Table 5. EDA/BLYP-D3/ZORA/TZ2P decomposition of the interaction energy of complexes into Pauli repulsion $\left(\mathrm{E}_{\mathrm{Pauli}}\right)$, electrostatic $\left(\mathrm{E}_{\text {elec }}\right)$, orbital interaction $\left(\mathrm{E}_{\mathrm{oi}}\right)$, and dispersion $\left(\mathrm{E}_{\mathrm{disp}}\right)$ terms. All energies are in $\mathrm{kcal} / \mathrm{mol}$. The relative values in percent express the contribution of each to the sum of all attractive energy terms. Geometries are taken from MP2 optimizations.

\begin{tabular}{|c|c|c|c|c|c|c|c|c|}
\hline System & $E_{\text {int }}$ & $\mathrm{E}_{\text {Pauli }}$ & $\mathrm{E}_{\text {elec }}$ & $\%$ & $\mathrm{E}_{\mathrm{oi}}$ & $\%$ & $E_{\text {disp }}$ & $\%$ \\
\hline HB & & & & & & & & \\
\hline 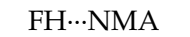 & -14.86 & 21.59 & -20.70 & 57 & -13.93 & 38 & -1.83 & 5 \\
\hline $\mathrm{ClH} \cdots \mathrm{NMA}$ & -11.46 & 28.82 & -20.22 & 50 & -17.21 & 43 & -2.85 & 7 \\
\hline BrH $\cdots \mathrm{NMA}$ & -11.21 & 33.58 & -21.17 & 47 & -20.34 & 45 & -3.29 & 7 \\
\hline $\begin{array}{c}\mathrm{IH} \cdots \mathrm{NMA} \\
\mathrm{XB}\end{array}$ & -8.87 & 37.65 & -21.44 & 46 & -21.53 & 46 & -3.55 & 8 \\
\hline FCl $\cdots \mathrm{NMA}$ & -14.07 & 32.53 & -22.40 & 48 & -21.91 & 47 & -2.29 & 5 \\
\hline 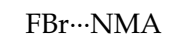 & -17.01 & 43.71 & -31.66 & 52 & -26.58 & 44 & -2.48 & 4 \\
\hline 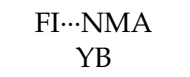 & -17.36 & 49.65 & -37.72 & 56 & -26.66 & 40 & -2.63 & 4 \\
\hline HFS $\cdots$ NMA & -10.85 & 25.45 & -18.92 & 52 & -14.72 & 41 & -2.66 & 7 \\
\hline HFSe $\cdots$ NMA & -12.75 & 35.40 & -26.27 & 55 & -19.05 & 40 & -2.83 & 6 \\
\hline $\begin{array}{c}\text { HFTe } \cdots \text { NMA } \\
\text { ZB }\end{array}$ & -13.91 & 42.18 & -32.62 & 58 & -20.26 & 36 & -3.21 & 6 \\
\hline $\mathrm{H}_{2} \mathrm{FP} \cdots \mathrm{NMA}$ & -8.04 & 20.43 & -15.78 & 55 & -9.91 & 35 & -2.79 & 10 \\
\hline $\mathrm{H}_{2} \mathrm{FAs} \cdots \mathrm{NMA}$ & -8.88 & 26.12 & -20.03 & 57 & -11.94 & 34 & -3.02 & 9 \\
\hline $\begin{array}{c}\mathrm{H}_{2} \mathrm{FSb} \cdots \mathrm{NMA} \\
\mathrm{TB}\end{array}$ & -10.59 & 32.23 & -25.76 & 60 & -13.93 & 33 & -3.13 & 7 \\
\hline $\mathrm{H}_{3} \mathrm{FSi} \cdots \mathrm{NMA}$ & -8.32 & 23.22 & -17.73 & 56 & -10.35 & 33 & -3.48 & 11 \\
\hline $\mathrm{H}_{3} \mathrm{FGe} \cdots \mathrm{NMA}$ & -7.88 & 25.96 & -19.82 & 59 & -10.51 & 31 & -3.51 & 10 \\
\hline $\mathrm{H}_{3} \mathrm{FSn} \cdots \mathrm{NMA}$ & -10.35 & 35.60 & -28.63 & 62 & -14.12 & 31 & -3.20 & 7 \\
\hline
\end{tabular}

Within the realm of the charge transfer, NBO offers a means of examining this phenomenon in more detail. The first column of Table 6 displays the energetic consequence of charge transfer from the lone pairs of the NMA O atom into the relevant $\sigma^{*}$ antibonding orbital of the Lewis acid, that is, $\sigma^{*}(\mathrm{HX})$ for $\mathrm{HB}$ and $\sigma^{*}(\mathrm{AF})$ for the others. These quantities are largest for the HB systems, and then diminish in the order of $\mathrm{XB}>\mathrm{YB}>\mathrm{ZB}>\mathrm{TB}$. Within each category, there is a general increasing trend with the size of the A atom, with some exceptions. A broader view of the charge transfer sums all of the interorbital interactions from base to acid. As seen in the next column of Table 6, these quantities are only slightly larger but follow similar trends. Rather than consider the energies of each transfer, one can simply evaluate the total charge transferred from base to acid. This quantity, designated as CT in Table 6, also follows the $\mathrm{XB}>\mathrm{YB}>\mathrm{ZB}>\mathrm{TB}$ trend, but in this case, the HB values are smaller than those computed for $\mathrm{XB}$ and $\mathrm{YB}$.

The strengths of these intermolecular bonds can also be measured via AIM analysis of the electron density topology. Some of the most common indicators are reported in Table S4 (Supplementary Materials). As is the case with the other measures described above, AIM verifies the general $\mathrm{HB}>\mathrm{XB}>$ $\mathrm{YB}>\mathrm{ZB}>\mathrm{TB}$ trend, as well as a tendency for stronger bonds to be associated with larger bridging A atoms. 
Table 6. NBO values $(\mathrm{kcal} / \mathrm{mol})$ of $\mathrm{E}(2)$ for $\mathrm{LP}(\mathrm{O})$ donation to the Lewis acid $\sigma^{*}$, orbital sum of all $\mathrm{E}(2)$ between NMA and LA, and total charge transfer (CT, in me) from NMA to LA obtained at the BLYP-D3/def2-TVZPP level.

\begin{tabular}{|c|c|c|c|}
\hline & $\mathrm{LP}(\mathrm{O}) \rightarrow \sigma^{* a}$ & $\Sigma($ base $\rightarrow$ acid $)$ & CT \\
\hline \multicolumn{4}{|l|}{ HB } \\
\hline FH $\cdots$ NMA & 29.85 & 31.22 & 66 \\
\hline $\mathrm{ClH} \cdots \mathrm{NMA}$ & 31.24 & 33.69 & 84 \\
\hline $\mathrm{BrH} \cdots \mathrm{NMA}$ & 39.14 & 43.25 & 105 \\
\hline 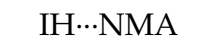 & 37.36 & 43.04 & 107 \\
\hline \multicolumn{4}{|l|}{$\mathrm{XB}$} \\
\hline $\mathrm{FCl} \cdots \mathrm{NMA}$ & 23.94 & 27.93 & 167 \\
\hline 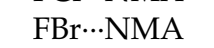 & 26.75 & 30.63 & 151 \\
\hline 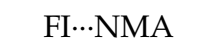 & 24.80 & 29.79 & 122 \\
\hline \multicolumn{4}{|l|}{ YB } \\
\hline HFS $\cdots$ NMA & 13.05 & 16.21 & 86 \\
\hline HFSe $\cdots$ NMA & 17.12 & 22.03 & 93 \\
\hline HFTe $\cdots$ NMA & 17.65 & 23.28 & 80 \\
\hline \multicolumn{4}{|l|}{$\mathrm{ZB}$} \\
\hline $\mathrm{H}_{2} \mathrm{FP} \cdots \mathrm{NMA}$ & 6.03 & 8.24 & 43 \\
\hline $\mathrm{H}_{2} \mathrm{FAs} \cdots \mathrm{NMA}$ & 10.41 & 13.32 & 54 \\
\hline $\mathrm{H}_{2} \mathrm{FSb} \cdots \mathrm{NMA}$ & 11.34 & 16.21 & 57 \\
\hline \multicolumn{4}{|l|}{ TB } \\
\hline $\mathrm{H}_{3} \mathrm{FSi} \cdots \mathrm{NMA}$ & 5.24 & 10.63 & 41 \\
\hline $\mathrm{H}_{3} \mathrm{FGe} \cdots \mathrm{NMA}$ & 7.30 & 12.78 & 41 \\
\hline $\mathrm{H}_{3} \mathrm{FSn} \cdots \mathrm{NMA}$ & 9.37 & 19.21 & 56 \\
\hline
\end{tabular}

\section{Computational Methods}

Full optimizations of isolated monomers and their complexes with NMA were performed at the MP2/aug-cc-pVDZ level of theory [63,64] (coordinates of obtained complexes are given in Table S5). For accurate electronic descriptions of the heavy I, Te, Sb, and $\mathrm{Sn}$ atoms, the aug-cc-pVDZ-PP basis set with pseudopotentials that include relativistic effects was taken from the EMSL library $[65,66]$. Frequency analysis confirmed these structures as true minima. The DFT BLYP-D3/Def2TZVPP [67,68] method was utilized in the NBO analysis (preceded by full geometry optimizations) so as to include electron correlation. CCSD(T)/aug-cc-pVDZ [69,70] single-point calculations, using MP2 geometries, provided a check on the MP2 energetics. Nuclear magnetic resonance (NMR) chemical shieldings were computed via the GIAO approach at the MP2 level. To provide full flexibility to the inner-shell electrons for purposes of NMR calculations, the all-electron Sapporo-DKH3-DZP-2012-diffuse [71] basis set, with relativistic effects included, was used for 4th row atoms, instead of the effective core potential of aug-cc-pVDZ-PP. Computations were carried out within the framework of the Gaussian09 suite of programs [72].

For isolated monomers, the maxima of molecular electrostatic potential (MEP) were located and visualized using MultiWFN and WFA-SAS programs on the 0.001 au electron density isosurface at the MP2 level [73-75]. Interaction energies of dimers were assessed as the difference in energy between the complex and the two monomers in their distorted geometry within the complex. The basis set superposition error (BSSE) was removed via the standard counterpoise procedure [76]. QTAIM analysis was employed to identify and quantify specific interconnections between monomers, using AIMAll Professional software [77]. NBO analysis (GenNBO 5.0) [78] was applied in order to measure charge transfers between orbitals and to compare natural charges before and after complexation. Decomposition of interaction energies was performed using the Morokuma-Ziegler EDA scheme implemented in the ADF program at the BLYP-D3/ZORA/TZ2P level [79-81]. Electron density shifts (EDSs) were visualized using the Chemcraft program. 


\section{Summary}

The calculations reveal that the various $\sigma$-hole noncovalent bonds do have certain spectroscopic properties similar to HBs. Just as the $\mathrm{X}-\mathrm{H}$ bond of the proton donor undergoes an elongation, and its stretching frequency shifts to the red and intensifies, the same occurs for the F-A bond of the Lewis acid. On the other hand, while each of these parameters intensifies as the halogen $X$ atom of the $\mathrm{XH}$ proton donor grows larger and the $\mathrm{HB}$ becomes weaker, the opposite trend of diminishing spectroscopic change occurs for the other noncovalent bonds with the larger $\mathrm{A}$ atom as the bond grows stronger. With respect to NMR chemical shielding, the HBs behave quite differently than do the others. While the bridging $\mathrm{H}$ atom is deshielded by $\mathrm{HB}$ formation, the other bridging atoms (whether $\mathrm{X}, \mathrm{Y}$, $\mathrm{Z}$, or $\mathrm{T}$ ) all increase their shielding. This shielding change rises quickly along with the size of the particular atom. There is also a strong deshielding noted on the $\mathrm{F}$ atoms that lie directly opposite each of these noncovalent bonds. It should be noted that the spectroscopic effects of the formation of these noncovalent bonds upon the Lewis acid when interacting with the NMA surrogate of a peptide bond are qualitatively similar to what was observed recently with the simpler but more powerful $\mathrm{NH}_{3}$ base [82].

The spectroscopic manifestations of HBs are much more similar to the other bonds within the Lewis base molecule NMA. In all cases, the $\mathrm{C}=\mathrm{O}$ bond of the amide is lengthened and its stretching frequency red-shifted and intensified. The amide II band, composed of a $\mathrm{C}-\mathrm{N}$ stretch and $\mathrm{N}-\mathrm{H}$ bend, shifts to higher frequency and undergoes a small band weakening. Like the overall bond strength, these effects are heightened by enlarging the bridging A atom. The NMR parameters of all types of bonds are very similar within the base. The shielding of the $\mathrm{O}$ atom directly involved in the bond rises by as much as $65 \mathrm{ppm}$, whereas the $\mathrm{C}$ and $\mathrm{N}$ atoms of the peptide group both undergo a shielding decrease in the range of 4-8 ppm. These changes rise in magnitude as the bridging $\mathrm{A}$ atom grows larger.

Both the frequency shifts of the amide I and II bands of the base as well as the shielding changes of the three pertinent NMA atoms correlate well with the strength of the noncovalent bond. There is thus some hope that spectroscopic measurements can serve not only as a marker for the presence of each of these types of bonds, but also as a gauge for its strength.

Supplementary Materials: The supplementary materials are available online. Figure S1: Electron Density Shifts calculated at the MP2. Purple indicates gain and loss is shown in green. Contours of $\Delta \rho= \pm 0.0005$ au on left and \pm 0.0015 au. on right, Table S1: NMR chemical shielding (ppm) of isolated monomers at MP2 level, Table S2: NMR chemical shielding (ppm) of isolated NMA molecule at MP2/aug-cc-pVDZ level, Table S3: NMR chemical shielding (ppm) for complexes at MP2 level, Table S4: AIM descriptors of complexes studied. Bond critical point $(\mathrm{BCP})$ properties: electron density $\rho$, Laplacian of electron density $\nabla^{2} \rho$, ellipticity $\varepsilon$, and total electron energy $\mathrm{H}$, were obtained at the MP2/aug-cc-pVDZ level. Data is given in atomic units, Table S5: Coordinates of complexes optimized at MP2/aug-cc-pVDZ level.

Author Contributions: Conceptualization, S.S. and W.Z.; methodology, S.S. and W.Z.; data curation, M.M., W.Z. and R.W.; writing - original draft preparation, S.S, W.Z and M.M.; writing—review and editing, S.S.; visualization, S.S., W.Z. and M.M., supervision, S.S.

Funding: This research was funded by Ministerstwo Nauki i Szkolnictwa Wyższego, grant number 049U/0045/19.

Acknowledgments: This work was financed in part by a statutory activity subsidy from the Polish Ministry of Science and Higher Education for the Faculty of Chemistry of Wroclaw University of Science and Technology. Generous computer time provided by the Wroclaw Supercomputer and Networking Center is acknowledged.

Conflicts of Interest: The authors declare no conflict of interest.

\section{References}

1. Hadzi, D.; Bratos, S. Vibrational Spectroscopy of the hydrogen bond. In The Hydrogen Bond. Recent Developments in Theory and Experiments; Schuster, P., Zundel, G., Sandorfy, C., Eds.; North-Holland Publishing Co.: Amsterdam, The Netherlands, 1976; Volume 2, pp. 565-611.

2. Gilli, G.; Gilli, P. The Nature of the Hydrogen Bond; Oxford University Press: Oxford, UK, 2009; p. 313.

3. Sponer, J.; Leszczynski, J.; Hobza, P. Hydrogen bonding and stacking of DNA bases: a review of quantum-chemical ab initio studies. Biomol. Struct. Dyn. 1996, 14, 117-135. [CrossRef] [PubMed] 
4. Scheiner, S. Hydrogen Bonding: A Theoretical Perspective; Oxford University Press: New York, NY, USA, 1997; p. 375.

5. Rivera-Rivera, L.A.; McElmurry, B.A.; Scott, K.W.; Lucchese, R.R.; Bevan, J.W. The Badger-Bauer Rule Revisited: Correlation of Proper Blue Frequency Shifts in the OC Hydrogen Acceptor with Morphed Hydrogen Bond Dissociation Energies in OC-HX (X = F, Cl, Br, I, CN, CCH). J. Phys. Chem. A 2013, 117, 8477-8483. [CrossRef] [PubMed]

6. Cook, J.L.; Hunter, C.A.; Low, C.M.R.; Perez-Velasco, A.; Vinter, J.G. Solvent effects on hydrogen bonding. Angew. Chem. Int. Ed. 2007, 46, 3706-3708. [CrossRef] [PubMed]

7. Du, L.; Mackeprang, K.; Kjaergaard, H.G. Fundamental and overtone vibrational spectroscopy, enthalpy of hydrogen bond formation and equilibrium constant determination of the methanol-dimethylamine complex. Phys. Chem. Chem. Phys. 2013, 15, 10194-10206. [CrossRef] [PubMed]

8. Boyer, M.A.; Marsalek, O.; Heindel, J.P.; Markland, T.E.; McCoy, A.B.; Xantheas, S.S. Beyond Badger's Rule: The Origins and Generality of the Structure-Spectra Relationship of Aqueous Hydrogen Bonds. J. Phys. Chem. Lett. 2019, 10, 918-924. [CrossRef] [PubMed]

9. Thatcher, R.J.; Johnson, D.G.; Slattery, J.M.; Douthwaite, R.E. Structure of Amido Pyridinium Betaines: Persistent Intermolecular C-H..N Hydrogen Bonding in Solution. Chem. Eur. J. 2016, 22, 3414-3421. [CrossRef] [PubMed]

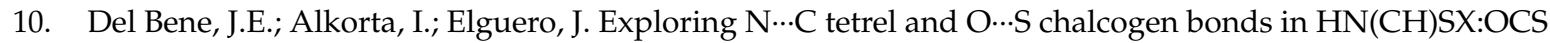
systems, for $\mathrm{X}=\mathrm{F}, \mathrm{NC}, \mathrm{Cl}, \mathrm{CN}, \mathrm{CCH}$, and H. Chem. Phys. Lett. 2019, 730, 466-471. [CrossRef]

11. Gougoula, E.; Medcraft, C.; Alkorta, I.; Walker, N.R.; Legon, A.C. A chalcogen-bonded complex $\mathrm{H}_{3} \mathrm{~N} \cdots \mathrm{S}=\mathrm{C}=\mathrm{S}$ formed by ammonia and carbon disulfide characterised by chirped-pulse, broadband microwave spectroscopy. J. Chem. Phys. 2019, 150, 084307. [CrossRef] [PubMed]

12. Alkorta, I.; Legon, A. An Ab Initio Investigation of the Geometries and Binding Strengths of Tetrel-, Pnictogen-, and Chalcogen-Bonded Complexes of $\mathrm{CO}_{2}, \mathrm{~N}_{2} \mathrm{O}$, and $\mathrm{CS}_{2}$ with Simple Lewis Bases: Some Generalizations. Molecules 2018, 23, 2250. [CrossRef] [PubMed]

13. Grabowski, S.J. Pnicogen and tetrel bonds-Tetrahedral Lewis acid centres. Struct. Chem. 2019, 30, 1141-1152. [CrossRef]

14. Grabowski, S. Tetrel Bonds with $\pi$-Electrons Acting as Lewis Bases-Theoretical Results and Experimental Evidences. Molecules 2018, 23, 1183. [CrossRef] [PubMed]

15. Alkorta, I.; Elguero, J.; Grabowski, S.J. Pnicogen and hydrogen bonds: complexes between $\mathrm{PH}_{3} \mathrm{X}^{+}$and $\mathrm{PH}_{2} \mathrm{X}$ systems. Phys. Chem. Chem. Phys. 2015, 17, 3261-3272. [CrossRef] [PubMed]

16. Franconetti, A.; Quiñonero, D.; Frontera, A.; Resnati, G. Unexpected chalcogen bonds in tetravalent sulfur compounds. Phys. Chem. Chem. Phys. 2019, 21, 11313-11319. [CrossRef] [PubMed]

17. Franconetti, A.; Frontera, A. Theoretical and Crystallographic Study of Lead(IV) Tetrel Bonding Interactions. Chem. Eur. J. 2019, 25, 6007-6013. [CrossRef]

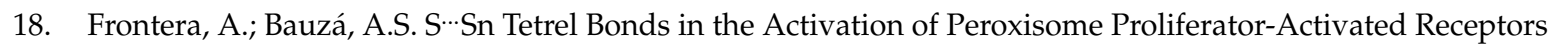
(PPARs) by Organotin Molecules. Chem. Eur. J. 2018, 24, 16582-16587. [CrossRef] [PubMed]

19. Murray, J.S.; Politzer, P. $\sigma-H o l e s$ and Si $\cdots \mathrm{N}$ intramolecular interactions. J. Mol. Model. 2019, 25, 101. [CrossRef] [PubMed]

20. Clark, T.; Murray, J.S.; Politzer, P. A perspective on quantum mechanics and chemical concepts in describing noncovalent interactions. Phys. Chem. Chem. Phys. 2018, 20, 30076-30082. [CrossRef]

21. Riley, K.E.; Tran, K.-A. Strength, character, and directionality of halogen bonds involving cationic halogen bond donors. Faraday Disc. 2017, 203, 47-60. [CrossRef]

22. Riley, K.E.; Vazquez, M.; Umemura, C.; Miller, C.; Tran, K.-A. Exploring the (Very Flat) Potential Energy Landscape of $\mathrm{R}-\mathrm{Br} \cdots \pi$ Interactions with Accurate $\mathrm{CCSD}(\mathrm{T})$ and SAPT Techniques. Chem. Eur. J. 2016, 22, 17690-17695. [CrossRef]

23. Scheiner, S. The pnicogen bond: Its relation to hydrogen, halogen, and other noncovalent bonds. Acc. Chem. Res. 2013, 46, 280-288. [CrossRef]

24. Zierkiewicz, W.; Michalczyk, M.; Wysokiński, R.; Scheiner, S. On the ability of pnicogen atoms to engage in both $\sigma$ and $\pi$-hole complexes. Heterodimers of $\mathrm{ZF}_{2} \mathrm{C}_{6} \mathrm{H}_{5}(\mathrm{Z}=\mathrm{P}, \mathrm{As}, \mathrm{Sb}, \mathrm{Bi})$ and $\mathrm{NH}_{3}$. J. Mol. Model. 2019, 25, 152. [CrossRef] [PubMed] 
25. Zierkiewicz, W.; Michalczyk, M.; Wysokiński, R.; Scheiner, S. Dual Geometry Schemes in Tetrel Bonds: Complexes between TF4 (T = Si, Ge, Sn) and Pyridine Derivatives. Molecules 2019, 24, 376. [CrossRef] [PubMed]

26. Zierkiewicz, W.; Fanfrlík, J.; Michalczyk, M.; Michalska, D.; Hobza, P. S...N chalcogen bonded complexes of carbon disulfide with diazines. Theoretical study. Chem. Phys. 2018, 500, 37-44. [CrossRef]

27. Dong, W.; Niu, B.; Liu, S.; Cheng, J.; Liu, S.; Li, Q. Comparison of $\sigma-/ \pi$-Hole Tetrel Bonds between $\mathrm{TH}_{3} \mathrm{~F} / \mathrm{F}_{2} \mathrm{TO}$ and $\mathrm{H}_{2} \mathrm{CX}(\mathrm{X}=\mathrm{O}, \mathrm{S}, \mathrm{Se})$. ChemPhysChem 2019, 20, 627-635. [CrossRef] [PubMed]

28. Dong, W.; Wang, Y.; Cheng, J.; Yang, X.; Li, Q. Competition between $\sigma$-hole pnicogen bond and $\pi$-hole tetrel bond in complexes of $\mathrm{CF}_{2}=\mathrm{CFZH}_{2}(\mathrm{Z}=\mathrm{P}, \mathrm{As}$, and Sb). Mol. Phys. 2019, 117, 251-259. [CrossRef]

29. Dong, W.; Li, Q.; Scheiner, S. Comparative Strengths of Tetrel, Pnicogen, Chalcogen, and Halogen Bonds and Contributing Factors. Molecules 2018, 23, 1681. [CrossRef] [PubMed]

30. Stasyuk, O.A.; Sedlak, R.; Guerra, C.F.; Hobza, P. Comparison of the DFT-SAPT and Canonical EDA Schemes for the Energy Decomposition of Various Types of Noncovalent Interactions. J. Chem. Theory Comput. 2018, 14, 3440-3450. [CrossRef] [PubMed]

31. Sedlak, R.; Eyrilmez, S.M.; Hobza, P.; Nachtigallova, D. The role of the s-holes in stability of non-bonded chalcogenide *-benzene interactions: the ground and excited states. Phys. Chem. Chem. Phys. 2018, 20, 299-306. [CrossRef]

32. Esrafili, M.; Mousavian, P. Strong Tetrel Bonds: Theoretical Aspects and Experimental Evidence. Molecules 2018, 23, 2642. [CrossRef]

33. Scheiner, S.; Adhikari, U. Abilities of different electron donors (D) to engage in a P...D noncovalent interaction. J. Phys. Chem. A 2011, 115, 11101-11110. [CrossRef]

34. Esrafili, M.D.; Mousavian, P.; Mohammadian-Sabet, F. Tuning of pnicogen and chalcogen bonds by an aerogen-bonding interaction: a comparative ab initio study. Mol. Phys. 2019, 117, 58-66. [CrossRef]

35. Cavallo, G.; Metrangolo, P.; Milani, R.; Pilati, T.; Priimagi, A.; Resnati, G.; Terraneo, G. The Halogen Bond. Chem. Rev. 2016, 116, 2478-2601. [CrossRef] [PubMed]

36. Syssa-Magale, J.L.; Boubekeur, K.; Schollhorn, B. First molecular self-assembly of 1,4-diiodo-tetrafluoro-benzene and a ketone via (O center dot center dot center dot I) non-covalent halogen bonds. J Mol Struct 2005, 737, 103-107. [CrossRef]

37. Del Bene, J.E.; Alkorta, I.; Elguero, J. Anionic complexes of $\mathrm{F}^{-}$and $\mathrm{Cl}^{-}$with substituted methanes: Hydrogen, halogen, and tetrel bonds. Chem. Phys. Lett. 2016, 655-656, 115-119. [CrossRef]

38. Scheiner, S. Can two trivalent $\mathrm{N}$ atoms engage in a direct $\mathrm{N} \cdots \mathrm{N}$ noncovalent interaction? Chem. Phys. Lett. 2011, 514, 32-35. [CrossRef]

39. Southern, S.A.; Bryce, D.L. NMR Investigations of Noncovalent Carbon Tetrel Bonds. Computational Assessment and Initial Experimental Observation. J. Phys. Chem. A 2015, 119, 11891-11899. [CrossRef] [PubMed]

40. Scheiner, S. Comparison of $\mathrm{CH} \cdots \mathrm{O}, \mathrm{SH} \cdots \mathrm{O}$, Chalcogen, and Tetrel Bonds Formed by Neutral and Cationic Sulfur-Containing Compounds. J. Phys. Chem. A 2015, 119, 9189-9199. [CrossRef] [PubMed]

41. Nziko, V.d.P.N.; Scheiner, S. Comparison of p-hole tetrel bonding with s-hole halogen bonds in complexes of $\mathrm{XCN}(\mathrm{X}=\mathrm{F}, \mathrm{Cl}, \mathrm{Br}, \mathrm{I})$ and $\mathrm{NH}_{3}$. Phys. Chem. Chem. Phys. 2016, 18, 3581-3590. [CrossRef]

42. Liu, M.; Li, Q.; Scheiner, S. Comparison of tetrel bonds in neutral and protonated complexes of pyridineTF 3 and furanTF $3(\mathrm{~T}=\mathrm{C}, \mathrm{Si}$, and $\mathrm{Ge})$ with $\mathrm{NH}_{3}$. Phys. Chem. Chem. Phys. 2017, 19, 5550-5559. [CrossRef]

43. Scheiner, S. Systematic Elucidation of Factors That Influence the Strength of Tetrel Bonds. J. Phys. Chem. A 2017, 121, 5561-5568. [CrossRef]

44. Bene, J.E.D.; Alkorta, I.; Elguero, J. Properties of cationic pnicogen-bonded complexes $\mathrm{F}_{4-n} \mathrm{H}_{n} \mathrm{P}^{+}: \mathrm{N}_{\text {-base }}$ with H-P..N linear and $\mathrm{n}=1-4$. Mol. Phys. 2016, 114, 102-117. [CrossRef]

45. Ellington, T.L.; Reves, P.L.; Simms, B.L.; Wilson, J.L.; Watkins, D.L.; Tschumper, G.S.; Hammer, N.I. Quantifying the Effects of Halogen Bonding by Haloaromatic Donors on the Acceptor Pyrimidine. ChemPhysChem 2017, 18, 1267-1273. [CrossRef]

46. Esrafili, M.D.; Vakili, M. The effect of hydrogen-bonding cooperativity on the strength and properties of б-hole interactions: an ab initio study. Mol. Phys. 2017, 115, 913-924. [CrossRef]

47. Gholipour, A.; Farhadi, S.; Neyband, R.S. Theoretical investigation of the nature and strength of simultaneous interactions of $\pi-\pi$ stacking and halogen bond including NMR, SAPT, AIM and NBO analysis. Struct. Chem. 2016, 27, 1543-1551. [CrossRef] 
48. Cormanich, R.A.; Rittner, R.; O'Hagan, D.; Bühl, M. Inter- and intramolecular CF ‥C=O interactions on aliphatic and cyclohexane carbonyl derivatives. J. Comput. Chem. 2016, 37, 25-33. [CrossRef]

49. Viger-Gravel, J.; Leclerc, S.; Korobkov, I.; Bryce, D.L. Correlation between ${ }^{13} \mathrm{C}$ chemical shifts and the halogen bonding environment in a series of solid para-diiodotetrafluorobenzene complexes. CrystEngComm 2013, 15, 3168-3177. [CrossRef]

50. Alkorta, I.; Sánchez-Sanz, G.; Elguero, J.; Del Bene, J.E. Influence of hydrogen bonds on the P...P pnicogen bond. J. Chem. Theory Comput. 2012, 8, 2320-2327. [CrossRef]

51. Ma, N.; Zhang, Y.; Ji, B.; Tian, A.; Wang, W. Structural competition between halogen bonds and lone-pair..p interactions in solution. ChemPhysChem 2012, 13, 1411-1414. [CrossRef]

52. Ghafari Nikoo Jooneghani, S.; Gholipour, A. Mutual cooperation of $\pi-\pi$ stacking and pnicogen bond interactions of substituted monomeric Lawesson's reagent and pyridine rings: Theoretical insight into Pyr||X-PhPS2 $\perp$ pyr complexes. Chem. Phys. Lett. 2019, 721, 91-98. [CrossRef]

53. Watson, B.; Grounds, O.; Borley, W.; Rosokha, S.V. Resolving the halogen vs hydrogen bonding dichotomy in solutions: intermolecular complexes of trihalomethanes with halide and pseudohalide anions. Phys. Chem. Chem. Phys. 2018, 20, 21999-22007. [CrossRef]

54. Xu, Y.; Gabidullin, B.; Bryce, D.L. Single-Crystal NMR Characterization of Halogen Bonds. J. Phys. Chem. A 2019, 123, 6194-6209. [CrossRef]

55. Barbas, R.; Prohens, R.; Bauzá, A.; Franconetti, A.; Frontera, A. H-Bonded anion-anion complexes in fentanyl citrate polymorphs and solvates. Chem. Commun. 2019, 55, 115-118. [CrossRef]

56. Mundlapati, V.R.; Sahoo, D.K.; Bhaumik, S.; Jena, S.; Chandrakar, A.; Biswal, H.S. Noncovalent Carbon-Bonding Interactions in Proteins. Angew. Chem. Int. Ed. 2018, 57, 16496-16500. [CrossRef]

57. Danelius, E.; Andersson, H.; Jarvoll, P.; Lood, K.; Gräfenstein, J.; Erdélyi, M. Halogen Bonding: A Powerful Tool for Modulation of Peptide Conformation. Biochem. 2017, 56, 3265-3272. [CrossRef]

58. Xia, Y.; Viel, S.; Wang, Y.; Ziarelli, F.; Laurini, E.; Posocco, P.; Fermeglia, M.; Qu, F.; Pricl, S.; Peng, L. Rationalizing the FS interaction discovered within a tetrafluorophenylazido-containing bola-phospholipid. Chem. Commun. 2012, 48, 4284-4286. [CrossRef]

59. Junming, L.; Yunxiang, L.; Subin, Y.; Weiliang, Z. Theoretical and crystallographic data investigations of noncovalent S...O interactions. Struct. Chem. 2011, 22, 757-963. [CrossRef]

60. Parisini, E.; Metrangolo, P.; Pilati, T.; Resnati, G.; Terraneo, G. Halogen bonding in halocarbon-protein complexes: A structural survey. Chem. Soc. Rev. 2011, 40, 2267-2278. [CrossRef]

61. Fick, R.J.; Kroner, G.M.; Nepal, B.; Magnani, R.; Horowitz, S.; Houtz, R.L.; Scheiner, S.; Trievel, R.C. Sulfur-Oxygen Chalcogen Bonding Mediates AdoMet Recognition in the Lysine Methyltransferase SET7/9. ACS Chem. Biol. 2016, 11, 748-754. [CrossRef]

62. Trievel, R.C.; Scheiner, S. Crystallographic and Computational Characterization of Methyl Tetrel Bonding in S-Adenosylmethionine-Dependent Methyltransferases. Molecules 2018, 23, 2965. [CrossRef]

63. Moller, C.; Plesset, M.S. Note on an approximation treatment for many-electron systems. Phys. Rev. 1934, 46, 0618-0622. [CrossRef]

64. Dunning, T.H. Gaussian-Basis Sets for Use in Correlated Molecular Calculations .1. The Atoms Boron through Neon and Hydrogen. J. Chem. Phys. 1989, 90, 1007-1023. [CrossRef]

65. Schuchardt, K.L.; Didier, B.T.; Elsethagen, T.; Sun, L.S.; Gurumoorthi, V.; Chase, J.; Li, J.; Windus, T.L. Basis set exchange: A community database for computational sciences. J. Chem. Inf. Model. 2007, 47, 1045-1052. [CrossRef]

66. Feller, D. The role of databases in support of computational chemistry calculations. J. Comput. Chem. 1996, 17, 1571-1586. [CrossRef]

67. Becke, A.D. Density-Functional Thermochemistry .3. The Role of Exact Exchange. J. Chem. Phys. 1993, 98, 5648-5652. [CrossRef]

68. Lee, C.T.; Yang, W.T.; Parr, R.G. Development of the Colle-Salvetti Correlation-Energy Formula into a Functional of the Electron-Density. Phys. Rev. B 1988, 37, 785-789. [CrossRef]

69. Purvis, G.D.; Bartlett, R.J. A full coupled-cluster singles and doubles model: The inclusion of disconnected triples. J. Chem. Phys. 1982, 76, 1910-1918. [CrossRef]

70. Raghavachari, K.; Trucks, G.W.; Pople, J.A.; Headgordon, M. A 5th-Order Perturbation Comparison of Electron Correlation Theories. Chem. Phys. Lett. 1989, 157, 479-483. [CrossRef] 
71. Noro, T.; Sekiya, M.; Koga, T. Segmented contracted basis sets for atoms H through Xe: Sapporo-(DK)-nZP sets ( $\mathrm{n}=\mathrm{D}, \mathrm{T}, \mathrm{Q})$. Theor. Chem. Acc. 2012, 131, 1124. [CrossRef]

72. Frisch, M.J.; Trucks, G.W.; Schlegel, H.B.; Scuseria, G.E.; Robb, M.A.; Cheeseman, J.R.; Scalmani, G.; Barone, V.; Mennucci, B.; Petersson, G.A.; et al. Fox Gaussian 09; Gaussian, Inc.: Wallingford, CT, USA, 2009.

73. Bulat, F.A.; Toro-Labbe, A.; Brinck, T.; Murray, J.S.; Politzer, P. Quantitative analysis of molecular surfaces: areas, volumes, electrostatic potentials and average local ionization energies. J. Mol. Model. 2010, 16, 1679-1691. [CrossRef]

74. Lu, T.; Chen, F. Quantitative analysis of molecular surface based on improved Marching Tetrahedra algorithm. J. Mol. Graphics Model. 2012, 38, 314-323. [CrossRef]

75. Lu, T.; Chen, F. Multiwfn: A multifunctional wavefunction analyzer. J. Comp. Chem. 2012, 33, 580-592. [CrossRef]

76. Boys, S.F.; Bernardi, F. Calculation of Small Molecular Interactions by Differences of Separate Total Energies-Some Procedures with Reduced Errors. Mol. Phys. 1970, 19, 553-566. [CrossRef]

77. Keith, A.T. AIMAll (Version 14.11.23); TK Gristmill Software: Overland Park, KS, USA, 2014.

78. Weinhold, F.; Landis, C.R.; Glendening, E.D. What is NBO analysis and how is it useful? Int. Rev. Phys. Chem. 2016, 35, 399-440. [CrossRef]

79. ADF2014, SCM, Theoretical Chemistry; Vrije Universiteit: Amsterdam, The Netherlands, 2014.

80. Te Velde, G.; Bickelhaupt, F.M.; Baerends, E.J.; Guerra, C.F.; Van Gisbergen, S.J.A.; Snijders, J.G.; Ziegler, T. Chemistry with ADF. J. Comput. Chem. 2001, 22, 931-967. [CrossRef]

81. Guerra, C.F.; Snijders, J.G.; Te Velde, G.; Baerends, E.J. Towards an order-N DFT method. Theor. Chem. Acc. 1998, 99, 391-403. [CrossRef]

82. Lu, J.; Scheiner, S. Effects of Halogen, Chalcogen, Pnicogen, and Tetrel Bonds on IR and NMR Spectra. Molecules 2019, 24, 2822. [CrossRef]

(C) 2019 by the authors. Licensee MDPI, Basel, Switzerland. This article is an open access article distributed under the terms and conditions of the Creative Commons Attribution (CC BY) license (http://creativecommons.org/licenses/by/4.0/). 